\title{
PREPARATION AND PERFORMANCE OF TANNIN-GLYOXAL-UREA RESIN-BONDED GRINDING WHEEL LOADED WITH SIO REINFORCING PARTICLES
}

\author{
Jun Zhang ${ }^{1}$ \\ https://orcid.org/0000-0003-1818-9182 \\ Bowen Liu ${ }^{1}$ \\ https://orcid.org/0000-0001-7843-7227 \\ Yunxia Zhou ${ }^{1}$ \\ https://orcid.org/0000-0001-7062-6875 \\ Hisham Essawy \\ https://orcid.org/0000-0003-2075-4216
}

Jinxin $\mathbf{L i}^{I}$

Qian Chen ${ }^{2, *}$

https://orcid.org/0000-0002-9636-9157

Xiaojian Zhoul, ${ }^{1, \$}$

https://orcid.org/0000-0002-7710-1892

Guanben $\mathrm{Du}^{1}$

https://orcid.org/0000-0002-8123-3484

\begin{abstract}
In this study, an easily prepared bio-based abrasive grinding wheel based on tannin-glyoxal-urea (TGU) thermosetting matrix is presented.The synthesised resin was prepared via co-polycondensation reaction of glyoxal and ureawith condensed tannin, which is a forest-derived product. Fourier transform infrared spectroscopy and electrospray ionisation mass spectrometry results confirmed that urea and glyoxal react well under acidic conditions and that $-(\mathrm{OH}) \mathrm{CH}-\mathrm{NH}$-group is primarily involved in TGU cross-linking. Differential scanning calorimetry, thermomechanical analysis and thermogravimetric analysis investigations showed that the preparation of TGU resin is easier compared to commercial phenol-formaldehyde (PF) resin; moreover, TGU resin has a more robust chemical network structure, which contributes efficiently to heat resistance and improved mechanical properties. This observation is supported by Brinell hardness, compression resistance and grinding testing; these showed that the new grinding wheel acquired higher hardness, superior resistance against compression and stronger abrasion resistance compared with a PFbased grinding wheel prepared in the laboratory. Moreover, few holes and no cracks were found in the new grinding wheel.
\end{abstract} \footnotetext{
biomass resources in Southwest of China, Kunming, China.

${ }^{3}$ National Research Centre, Department of Polymers and Pigments, Dokki, Cairo, Egypt.

•Corresponding authors: chenqian@hit.edu.cn ; xiaojianzhou1982@163.com

Received: 10.09.2020 Accepted: 19.04.2021
}

${ }^{1}$ Southwest Forestry University, Yunnan Key Laboratory of Wood Adhesives and Glued Products, Kunming, China.

${ }^{2}$ Southwest Forestry University, Key Laboratory of State forestry and Grassand Administration on highly efficient utilisation of forestry 
Keywords: Bark, bio-based resin, glyoxal, grinding wheel, mimosa, tannin, urea.

\section{INTRODUCTION}

Grinding wheels are frequently used for processing materials in construction, interior decoration, mechanical manufacturing and other fields (Li et al. 2020, Klocke et al. 2015, Manoharan et al. 2015). For three decades, phenol-formaldehyde (PF) resin has been widely employed as a binder for the preparation of abrasive materials (Robie 1957, Rowse and Stinchfield 1959, Wang et al. 2011, Luo et al. 2012). However, the release of free formaldehyde during preparation and use cause environmental pollution, limiting its industrial application. Therefore, considerable research has been performed on tannin originating from forests (Pizzi 1994, Pasch et al. 2001) to develop a new environmentally friendly and low-cost resin as a substitute for preparing grinding wheels. The chemical structure of mimosa tannin (MT) is analogous to that of phenol (Zuo et al. 2019, Tondi et al. 2008a, Tondi et al. 2008b) and predominantly comprises prorobinetinidins and profisetinidins (Figure 1). The reactivity at positions 6 and 8 of aromatic ring A is high; thus, electrophilic substitution with cations is easy. In contrast, at position 4 of aromatic ring A, nucleophilic substitution with anions is most favourable. Electrophilic activity at position 8 is higher compared to that at position 6 because position 8 is closer to heteroepoxy in aromatic ring A (Tondi et al. 2008c).

Over the preceding three decades, tannin has been widely studied to partially or completely replace phenol in PF resin to reduce the cost and use of oil-derived materials as processing aids (Hussein et al. 2011, Moubarik et al. 2009). However, compared with phenol, condensed tannin has more number of phenolic hydroxyl groups and a complex structure along with poor mechanical properties and low reactivity. Therefore, cross-linking between tannin and formaldehyde resulted in reasonable mechanical properties (Sauget et al. 2014). Furthermore, furfuryl alcohol was used instead of formaldehyde to react with condensed tannin to obtain a non-toxic bio-based tannin-furanic acid (TF) thermosetting resin, which is used for the fabrication of grinding wheels (Zhang et al. 2015, Lagel et al. 2015a), rigid plastic (Li et al. 2013), foams (Zhou et al. 2019, Celzard et al. 2010, Lacoste et al. 2013, Lacoste et al. 2014) and wood adhesives (Abdullah and Pizzi 2013). Although TF resin-based products have high hardness and excellent mechanical properties, the high price of furfuryl alcohol constrains their industrial application. Glyoxal is a less toxic aldehyde (Wu et al. 2016) that can be used as an alternative cross-linker to react with tannin under acidic conditions instead of furfuryl alcohol and formaldehyde. However, tannin-glyoxal (TG) resin prepared in the laboratory has low viscosity and weak water resistance (Zhang et al. 2019). In contrast, urea is inexpensive, has good reactivity and can be reacted with tannin and glyoxal to form a high molecular weight condensate with improved mechanical properties (Li et al. 2015, Beckert et al. 2015). Consequently, research on tannin, glyoxal and urea focused on ascertaining the feasibility of tannin-glyoxal-urea (TGU) resin-based abrasive grinding wheels with high hardness, enhanced water resistance and good mechanical properties.

This study focuses on developing an environmentally friendly abrasive grinding wheel to replace the industrially comparable PF-based grinding wheel. First, urea and glyoxal were reacted to form GU resin under acidic conditions. Next, tannin was incorporated to yield TGU resin. Then, silicon dioxide $\left(\mathrm{SiO}_{2}\right)$ particles were mixed into the resin matrix. Previously, sample curing was achieved in an oven over 4 days (Lagel et al. $2015 b$ ), whereas the current method has made the fabrication process more efficient and simplified by mixing the resin with abrasive particles and conducting the curing in a press in a shortened time $(\sim 1,5 \mathrm{~h})$. 


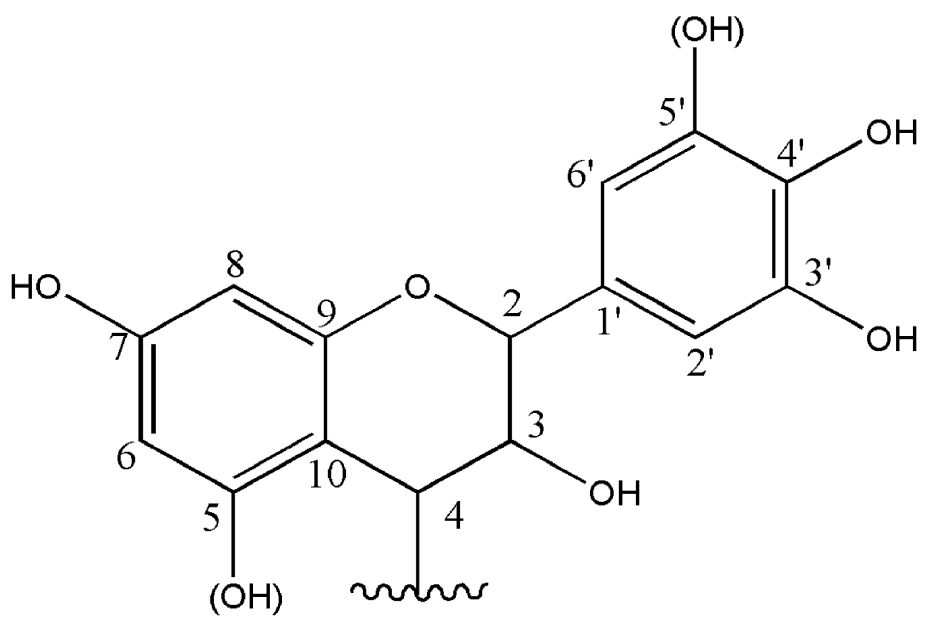

Figure 1: Chemical structure of mimosa tannin (MT).

\section{MATERIALS AND METHODS}

\section{Materials}

Tannin powder, extracted from mimosa bark (Caciamearnsii mollissima De Wildt), was purchased from Hong Bang Biological Technology Co. (Chuxiong, China). Glyoxal (40 \%), 37 \% aqueous solution of formaldehyde, para-toluene-4-sulphonic acid (p-TSA; 97,5\%) and furfuryl alcohol (98\%) were provided byAcros Organics (Geel, Belgium), while ethanol ( $80 \%$ ) was purchased from Sinopharm Chemical Reagent Company (Beijing, China). SiO, particles $(0,4 \mathrm{~mm}$ in size) and commercial tung oil were supplied by the Run Xin Materials Co. (Kunming, China). Commercial urea was procured from Huairenzhongan Chemical Plant (Jiangxi, China) while liquefied phenol (80 \%) and sodium hydroxide were procured from Fisher Scientific (Loughborough, UK).

\section{Preparation of different resin matrices}

First, $100 \mathrm{~g}$ of tannin powder and $500 \mathrm{~mL}$ of ethanol were mixed for $1 \mathrm{~h}$ at room temperature $\left(27^{\circ} \mathrm{C}\right)$ under continuous stirring. After extraction, the mixture was centrifuged, and the supernatant was collected. Ethanol was removed in a rotary evaporator at $60^{\circ} \mathrm{C}$. MT was obtained after the removal of entrapped water via freeze-drying of the remaining product.

The TGU resin matrix was synthesised as follows. Glyoxal and urea were mixed at a G/U molar ratio of 2 in a flat-bottomed flask according to the literature of Deng et al. (2014a), Deng et al. 2014b, equipped with a thermometer and a magnetic stirrer bar for $30 \mathrm{~min}$ at $80^{\circ} \mathrm{C}$, and the $\mathrm{pH}$ was adjusted to $10 \mathrm{using} 40 \%$ aqueous solution of $\mathrm{NaOH}$. Then, the temperature was decreased to $60^{\circ} \mathrm{C}$ and $\mathrm{MT}$ was added under continuous stirring for $30 \mathrm{~min}$. The mixture was loaded into a rotary evaporator and worked on under vacuum for 1,5 $\mathrm{h}$, during the process, the $\mathrm{pH}$ was adjusted to 3 or 10 using $30 \%$ aqueous solution of p-TSA or $40 \%$ aqueous solution of $\mathrm{NaOH}$ to form TGU1 or TGU2 resin, respectively. To decrease resin brittleness, tung oil was added to both resins as described by Lagel et al. (2015a).

TF and PF resins were prepared for the purpose of comparison with TGU resin. The TF resin matrix was prepared as described by Li et al. (2013) and Lagel et al. (2015b). Thus, MT and furfuryl alcohol were mixed in a beaker under continuous stirring for $5 \mathrm{~min}$, and the $\mathrm{pH}$ was adjusted to 3 using $30 \%$ aqueous solution of $\mathrm{p}$-TSA. Then, the mixture was transferred to a rotary evaporator and worked on under vacuum for $1,5 \mathrm{~h}$ at 60 ${ }^{\circ} \mathrm{C}$. Tung oil was added to obtain TF resin. The formulations employed for the preparation of the tannin-based resin matrices are presented in Table 1. 
Table 1: Composition of the tannin-based resin matrices prepared in this study.

\begin{tabular}{|c|c|c|c|c|c|}
\hline Sample & MT (g) & Furfuryl alcohol (mL) & Glyoxal $(\mathrm{mL})$ & Urea $(\mathrm{g})$ & Tung oil $(\mathrm{mL})$ \\
\hline TGU1 & 20 & $/$ & 38 & 20 & 5 \\
\hline TGU2 & 20 & $/$ & 38 & 20 & 5 \\
\hline TF & 20 & 60 & $/$ & $/$ & 5 \\
\hline
\end{tabular}

MT refers to mimosa tannin.

PF resin was synthesised at $94{ }^{\circ} \mathrm{C}$ as described previously (Rowse and Stinchfield 1959). 2 mol of formaldehyde ( $37 \%$ aqueous solution) was mixed with $1 \mathrm{~mol}$ of phenol. The formaldehyde was divided into four equal parts, and each part was added at 15-min intervals. The first part of formaldehyde was mixed with phenol in a flask and put into an induction oven at $94{ }^{\circ} \mathrm{C}$ under continuous stirring, whereas the second, third and fourth parts of formaldehyde were added into the induction oven and the mixture was refluxed under continuous stirring. During this process, the $\mathrm{pH}$ was adjusted to 10 using $40 \%$ aqueous solution of $\mathrm{NaOH}$.

The solid content in the resin matrices were determined by recording the weight of the resins before and after drying for $2 \mathrm{~h}$ in an oven at $120^{\circ} \mathrm{C} \pm 1{ }^{\circ} \mathrm{C}$. A TU 4 viscosity cup was used to assess the viscosity of the resins at room temperature while their curing time was determined in accordance with Chinese National Standard GB/T14074 (2006).

\section{Preparation of the grinding wheels}

Grinding wheels were prepared as previously described by Lagel et al. (2015b). First, $50 \mathrm{~g}$ of either TGU1, TGU2, TF or PF resin was put in a beaker with $\mathrm{SiO}_{2}$ particles at $\mathrm{SiO}_{2}$-to-resin mass ratio of 1,5:1. Mixing was performed under continuous stirring for $5 \mathrm{~min}$. Next, the mixture was put into a mould $(50 \mathrm{~mm}$ in diameter and $15 \mathrm{~mm}$ in thickness) and the mould was placed in a press machine for $1,5 \mathrm{~h}$ at $150{ }^{\circ} \mathrm{C}$ under a pressure of 7,8 $\mathrm{MPa}$. Cooling at room temperature was employed and a 16- $\mathrm{mm}$ diameter hole was drilled at the centre to produce a grinding wheel; the TGU1-, TGU2-, TF-and PF-based grinding wheels are termed TGU1-G, TGU2-G, TF-G and PF-G, respectively. Figure 2 illustrates the steps involved in the preparation of TGU-G.

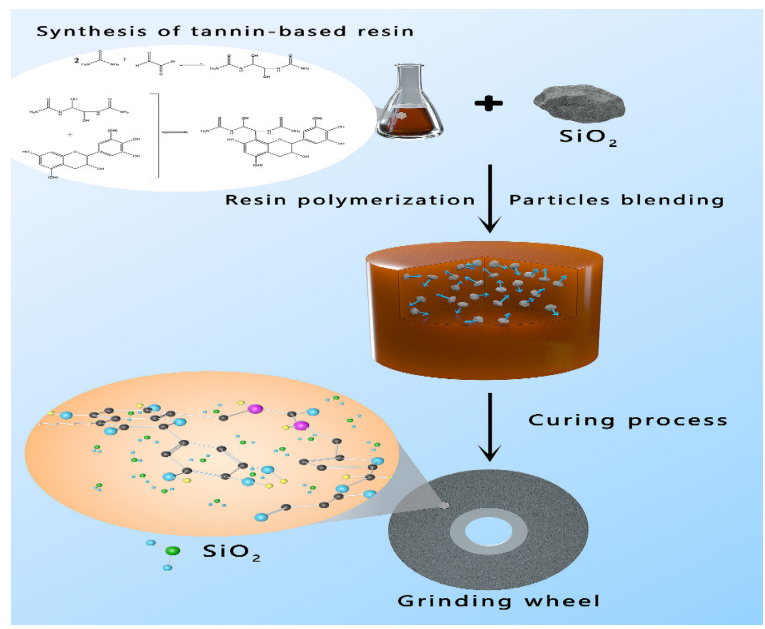

Figure 2: Preparation of a grinding wheel based on TGU1 resin and $\mathrm{SiO}_{2}$ particles.

\section{Characterizations}

\section{Fourier transform infrared spectroscopy}

Fourier transform infrared (FTIR) spectroscopy was performed on the resins using a Varian 1000 infrared spectrometer (Varian, Palo Alto, CA, USA) to record the relevant spectra over a wavenumber range of 500 $\mathrm{cm}^{-1}-4000 \mathrm{~cm}^{-1}$. Sample preparation for the acquisition of spectra involved mixing $0,001 \mathrm{~g}$ of $\mathrm{KBr}$ with $0,1 \mathrm{~g}$ 
of finely ground particles of each cured resin.

\section{Electrospray ionisation mass spectrometry}

Electrospray ionisation mass spectrometry (ESI-MS) was performed on a Waters Xevo Triple Quadrupole-MS (Waters, Milford, MA, USA) equipped with an ESI source. Samples of $N$-(2)-L-alanyl-L-glutamine, MT, TGU1resin and their mixtures were sequentially dissolved in chloroform at a concentration of $\sim 10 \mu \mathrm{L} /$ $\mathrm{mL}$ and injected using a syringe at a flow rate of $5 \mu \mathrm{g} / \mathrm{s}$ into the ESI source connected to an ion trap mass spectrometer (Bruker Daltonics Inc., Billerica, MA, USA). The spectra were recorded in positive mode with ion energy of $4,8 \times 10^{-20} \mathrm{~J}$ over a scan range of up to $1000 \mathrm{Da}$.

\section{Differential scanning calorimetry}

A differential scanning calorimeter (Netzsch DSC 204 F1, Germany) was used to study the curing behaviour of the resins under nitrogen atmosphere at a heating rate of $15^{\circ} \mathrm{C} / \mathrm{min}$ over a temperature range of 30 ${ }^{\circ} \mathrm{C}-250{ }^{\circ} \mathrm{C}$.

\section{Thermomechanical analysis}

The elasticity modulus of the tannin-based resins was determined via thermomechanical analysis (TMA SDTA840, Mettler-Toledo, NY-USA); the obtained were processed using STARe software version 14.0 (Mettler-Toledo) for samples measuring $21 \times 6 \times 1,2 \mathrm{~mm}^{3}$. The runs proceeded from r.t. to $250{ }^{\circ} \mathrm{C}$ at a heating rate of $20^{\circ} \mathrm{C} / \mathrm{min}$.

\section{Thermogravimetric analysis}

To identifythe thermal resistance of the tannin-based grinding wheels, thermogravimetric analysis (TGA) was performed using a TG 209 F3 thermogravimetric analyser (Netzsch) operated under nitrogen atmosphere. The heating rate was $20{ }^{\circ} \mathrm{C} / \mathrm{min}$ and the run covered a temperature range of $30{ }^{\circ} \mathrm{C}-900{ }^{\circ} \mathrm{C}$.

\section{Scanning electron microscopy}

Samples measuring $5 \times 5 \times 4 \mathrm{~mm}^{3}$ were observed using a Hitachi scanning electron microscope (model S4800, Tokyo, Japan) at $50 \times$ magnification.

\section{Brinell hardness and compression of grinding wheels}

Brinell hardness $\left(H_{\mathrm{B}}, \mathrm{Da} \mathrm{N} / \mathrm{mm}^{2}\right)$ values were assigned in accordance with Chinese National Standard GB/T 231.1-2009 (2009) using a strength testing machine (Instron 1193, Boston, MA, USA) with a 10-mm steel ball under a load of $2452 \mathrm{~N}$ at a loading rate of $2 \mathrm{~mm} / \mathrm{min} . H_{\mathrm{B}}$ was calculated using the following equation, and the averaged value for the six samples was used Equation 1.

$$
H B=\frac{3,18}{1000} \times \frac{F}{P}
$$

Where $F$ is the force that met the retained depression requirement $(\mathrm{N})$ and $P$ is the depth of ball depression $(\mathrm{mm})$.

Compression was implemented in accordance with ASTM D695-10 (2010) using the same strength testing machine at a load ingrate of $2 \mathrm{~mm} / \mathrm{min}$. The averaged value for the six samples was used.

\section{Abrasion of grinding wheels}

The wear index $(I, \%)$ of the grinding wheels was determined in accordance with ASTM-D4060-01 (2010) by recording the mass loss exhibited by a commercial particleboard $\left(100 \times 100 \times 19 \mathrm{~mm}^{3}\right)$ after completing 500 abrasion cycles through a Taber Abraser 5130 abrasimeter (Taber Industries, North Tonawanda, NY, USA). Wet abrasion was performed in accordance with ASTM-D4060-01 (2010) after immersing the samples in boiling water for $30 \mathrm{~min}$. In addition, a commercial calibrated H-18 grinding wheel (Taber Industries; parti- 
cle-to-resin mass ratio of 1,5:1) was used for comparison. $I$ was calculated according to the following equation as the average value of six samples Equation 2.

$$
I=\frac{(A-B) \times 1000}{C}
$$

Where $A$ is the weight of the particleboard before abrasion (mg), $B$ is the weight of the particleboard after abrasion (mg) and $C$ is the number of abrasion cycles.

\section{RESULTS AND DISCUSSION}

\section{FTIR and ESI-MS analyses}

Figure 3 shows the infrared spectra of tannin-glyoxal-urea (TGU1) resin compared with that of MT. The spectrum of MT shows O-H stretching, which appears as a broad band at $3600 \mathrm{~cm}^{-1}-3400 \mathrm{~cm}^{-1}$. Absorption bands at $1614 \mathrm{~cm}^{-1}, 1557 \mathrm{~cm}^{-1}, 1521 \mathrm{~cm}^{-1}$ and $1451 \mathrm{~cm}^{-1}$ are assigned to aromatic $\mathrm{C}=\mathrm{C}$ stretching. In addition, aromatic $\mathrm{C}=\mathrm{C}$ stretching of TGU1 resin was confirmed by peaks at $1452 \mathrm{~cm}^{-1}$ and $1401 \mathrm{~cm}^{-1}$. The $\mathrm{C}-\mathrm{O}$ stretching of phenols in the MT structure is represented by an absorption band at $1284 \mathrm{~cm}^{-1}$, while in case of TGU1, it is represented by two absorption bands at $1225 \mathrm{~cm}^{-1}$ and $1207 \mathrm{~cm}^{-1}$. The MT spectrum exhibited an overtone of $\mathrm{C}-\mathrm{H}$ stretching bands for the aromatic species at $1160 \mathrm{~cm}^{-1}-1042 \mathrm{~cm}^{-1}$ and was slightly s hifted to $1162 \mathrm{~cm}^{-1}-1039 \mathrm{~cm}^{-1}$ for TGU1. These results indicate that urea and glyoxal caused a change in the chemical environment of the pure MT structure, translated into peak shifts. For verification, the spectrum of TGU1 was characterised by a broadened band extending over $3600 \mathrm{~cm}^{-1}-3200 \mathrm{~cm}^{-1}$, attributed to overlapping $\mathrm{O}-\mathrm{H}$ and $\mathrm{N}-\mathrm{H}$ stretching. A carbonyl band at $1718 \mathrm{~cm}^{-1}$ refers to unreacted glyoxal, while the bands at 1654 $\mathrm{cm}^{-1}$ attributed to $\mathrm{C}=\mathrm{N}$ stretching or the $\mathrm{C}=\mathrm{O}$ stretching in the urea and $1342 \mathrm{~cm}^{-1}$ indicate the presence of $\mathrm{C}-\mathrm{N}$ stretching, respectively.
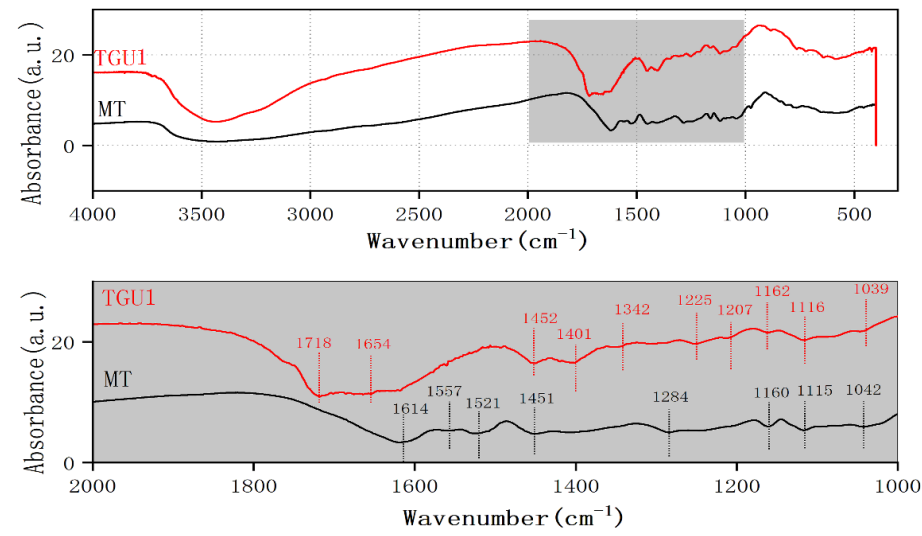

Figure 3: FTIR spectra of MT and TGU1 resin.

Figure 4 shows the results of ESI-MS analysis for the detected fractions derived from MT and TGU1 resin, generated by the co-polymerisation of MT, glyoxal and urea. In the mass spectrogram, the abscissa represents the mass-to-charge ratio $(\mathrm{m} / \mathrm{z})$ of ions bearing a single charge, with values increasing from left to right, whereas the ordinate represents the ion flow population. Table 2 presents the main chemical fractions resulting from MT and TGU1 resin. All peak values are based on either the molecular weight of the species + 23 because of an $\mathrm{Na}^{+}$ion of the $\mathrm{NaCl}$ matrix enhancer or the molecular weight of the species +1 because of $\mathrm{H}^{+}$ protonation. Formation of several possible intermediates can be deduced, as shown in Table 2. 
In particular, the reaction between tannin and glyoxal was proven under the present reaction conditions via the detection of positive ions at $\mathrm{m} / \mathrm{z} 385\left((\mathrm{M}+\mathrm{Na})^{+}\right)$(Figure 5a). In addition, the phloroglucinol reaction complies with positive ions at $m / z 157\left((\mathrm{M}+\mathrm{H})^{+}\right)$, which could be produced by tannin monomer degradation. A ring-opening reaction occurred due to the presence of positive ions at $m / z 365\left((\mathrm{M}+\mathrm{H})^{+}\right)$(Figure $\left.5 \mathrm{~b}\right)$. Furthermore, the reaction between tannin, glyoxal and urea matched the positive ions at $\mathrm{m} / \mathrm{z} 701\left((\mathrm{M}+\mathrm{Na})^{+}\right)$. Therefore, peaksat $m / z 1663\left((\mathrm{M}+\mathrm{H})^{+}\right)$and $1887\left((\mathrm{M}+\mathrm{H})^{+}\right)($Figure 5c, 5d) are assigned to the reaction between tannin multimer, glyoxal and urea. All FTIR and ESI-MS results confirmed that the reactions between tannin, glyoxal and urea under acidic conditions were successful.

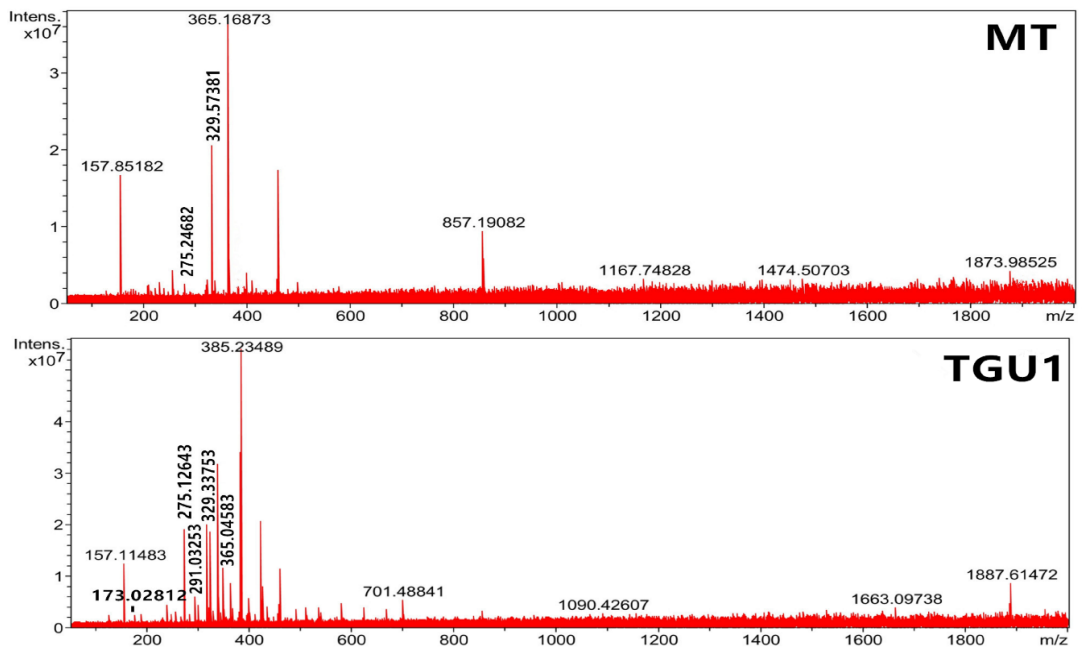

Figure 4: ESI-MS spectra of MT and TGU1 resin. 
Table 2: Oligomers identified via ESI-MS for the reaction between MT, glyoxal and urea.

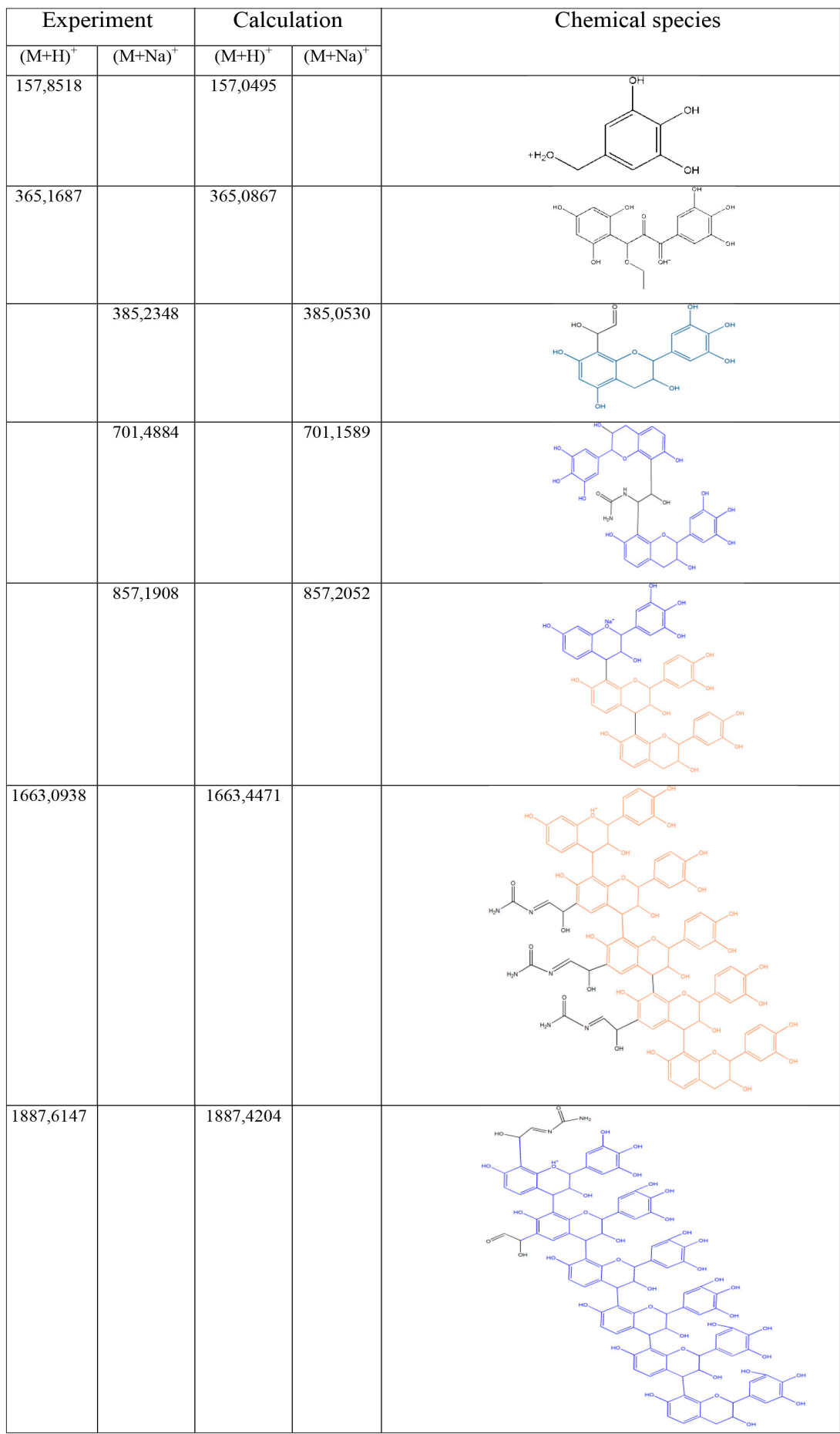



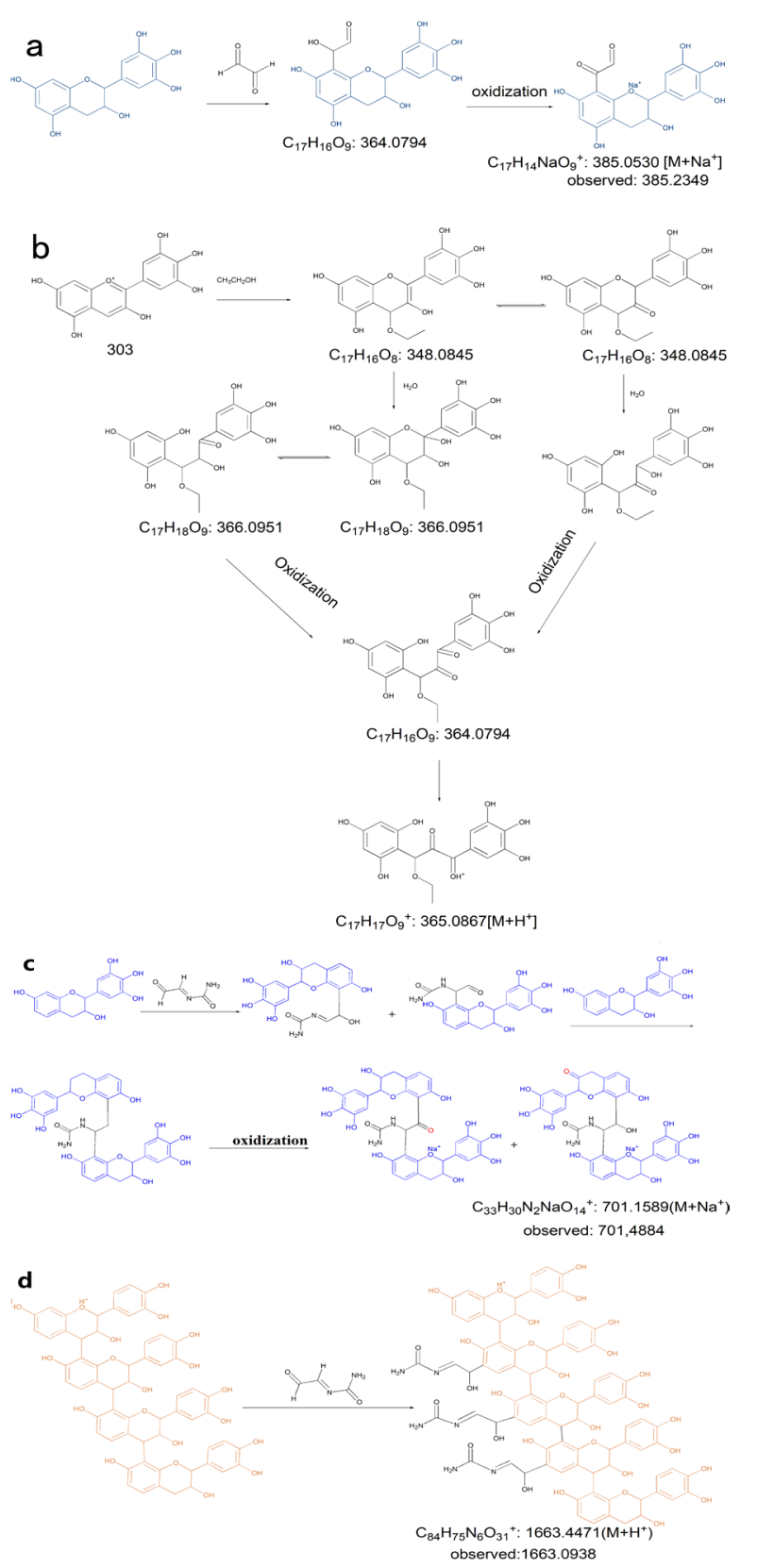

Figure 5: Proposed condensation reactions of the tannin-based resin system.

\section{Characteristics of various laboratory resin matrices}

The general characteristics of the resins synthesised in the laboratory are presented in Figure 6 . The viscosity of the TF resin was higher compared to that of TGU1 and TGU2 resins despite the higher solid content in TGU1 and TGU2 resins compared to TF resin; this can be attributed to better connectivity between the chains of TF through secondary forces and hydrogen bonding. In addition, linear chains of TF are longer than those of other resins. The involvement in glyoxal and urea with tannin can cause high levels of branching, which might cause a drop in viscosity. However, some researchers (Pizzi et al. 2008, Tondi 2017) have suggested that during the preparation of TF resin at $60^{\circ} \mathrm{C}$ under acidic conditions, it is difficult to build a $-\mathrm{CH}_{2}-$ bridge because of the self-condensation of furfuryl alcohol and high viscosity owing to the presence of tannin residue in the resin.

The solid content of TGU1 was higher compared to TGU2, matching a longer gel time of TGU2 with respect to TGU1, indicating that glyoxal is easily converted to tetrahydroxy ethane after a hydration-reversible 
reaction in water under acidic conditions and then reacts with urea to synthesise GU resin for further co-polymerisation with MT. Therefore, compared to alkaline conditions, the reaction between tannin, furfuryl alcohol, urea and glyoxal is easily established under acidic conditions to form a resin system.

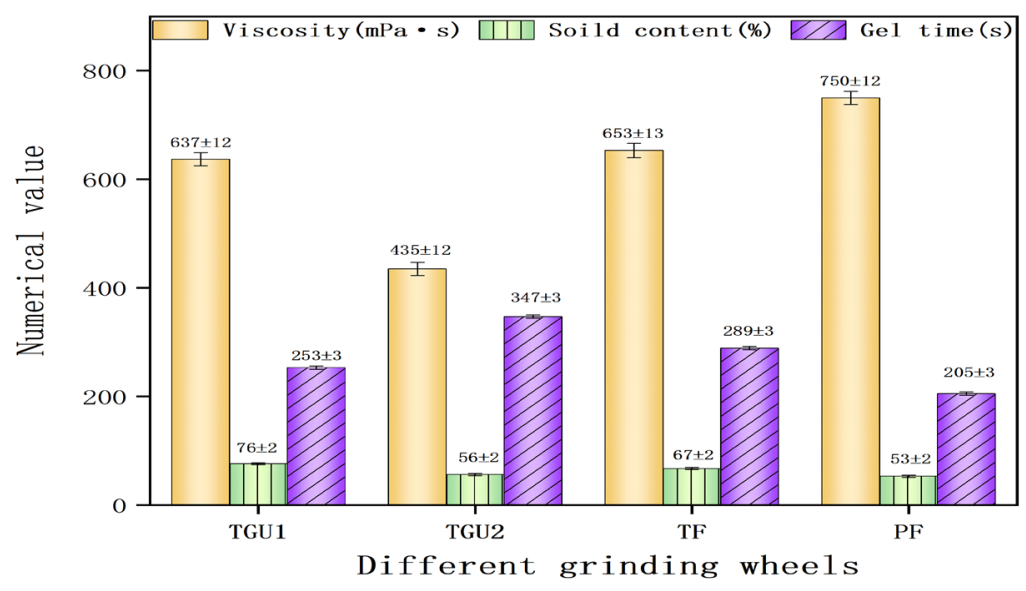

Figure 6: Fundamental characteristics of various resin matrices.

Curing thermograms of TGU1, TGU2, TF and PF resins are shown in Figure 7. The TGU2 reaction proceeded in two exothermic steps, indicating that two types of condensation formed in sequence. The reaction of TGU is slow in general because of the low reactivity of MT with GU resin, especially under alkaline conditions. The first peak at $87^{\circ} \mathrm{C}$ was attributed to the straight chain reaction between glyoxal and urea under alkaline conditions (Deng et al. 2014b, Li and Lee 2000). As the temperature increased, MT began to react with GU more vigorously to build up a network structure. We strongly believe that this is due to the direct and instant connectivity between the two peaks (no induction time was noticed between them). In contrast, only one exothermic peak was observed for TGU1 resin at $100^{\circ} \mathrm{C}-110^{\circ} \mathrm{C}$, indicating that the reaction between MT and GU resin under acidic conditions is easier, more homogeneous and favourable than under alkaline conditions. Moreover, the temperature of maximum curing peak of TGU1 resin $\left(97^{\circ} \mathrm{C}\right)$ are shorter than that of TF resin $\left(103^{\circ} \mathrm{C}\right)$, indicating that TGU1 resin is easier to prepare than $\mathrm{TF}$ resin.

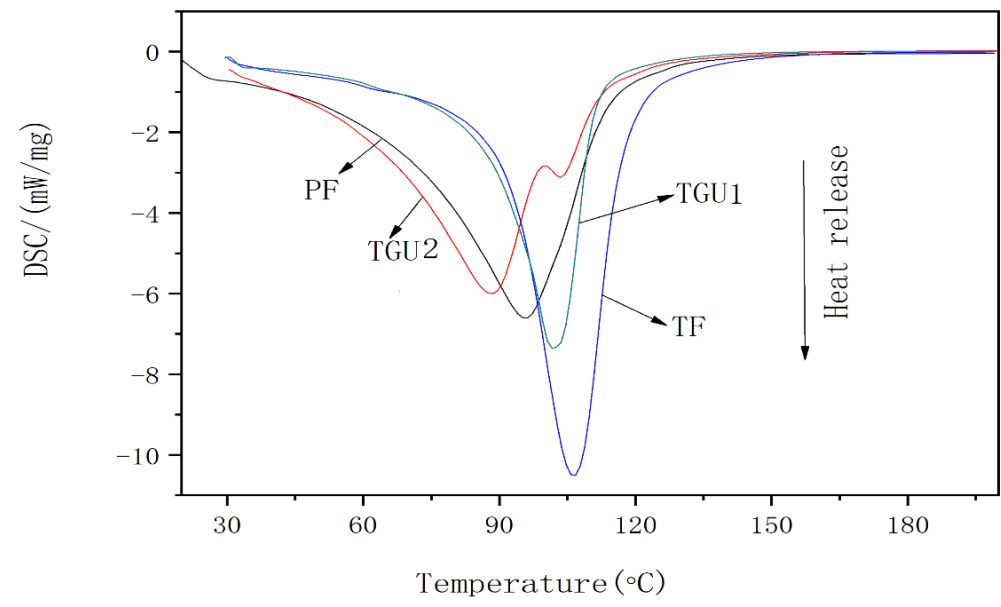

Figure 7: Curing exotherms of tannin-based resins and PF resin using differential scanning calorimetry. 
This can be accounted for by higher reactivity between MT, urea and glyoxal under acidic conditions leading to a stronger network structure as corroborated by the sharpness of the curing peak, which can also be correlated with the gel time data (Figure 4) and investigation by TMA in Figure 8 . The cross-linking between MT and furfuryl alcohol can proceed smoothly at a higher temperature as compared to the reaction between MT, urea and glyoxal to produce a resin with reasonable reactivity and balanced strength. The extended area under the peak corroborates the loose structure of the resin network as compared to TGU1 and explains the weaker mechanical strength, at least with respect to TGU1, which exhibited the maximum strength (compare TMA profiles in Figure 8). In the case of $\mathrm{SiO}_{2}$ particles, it is expected that efficient chemical bonding to the network structure can develop through their surface hydroxyl groups, in particular with TGU1, leading to outstanding strength compared to the other resins. Further extensive thermal studies are required for detailed investigation of this point.

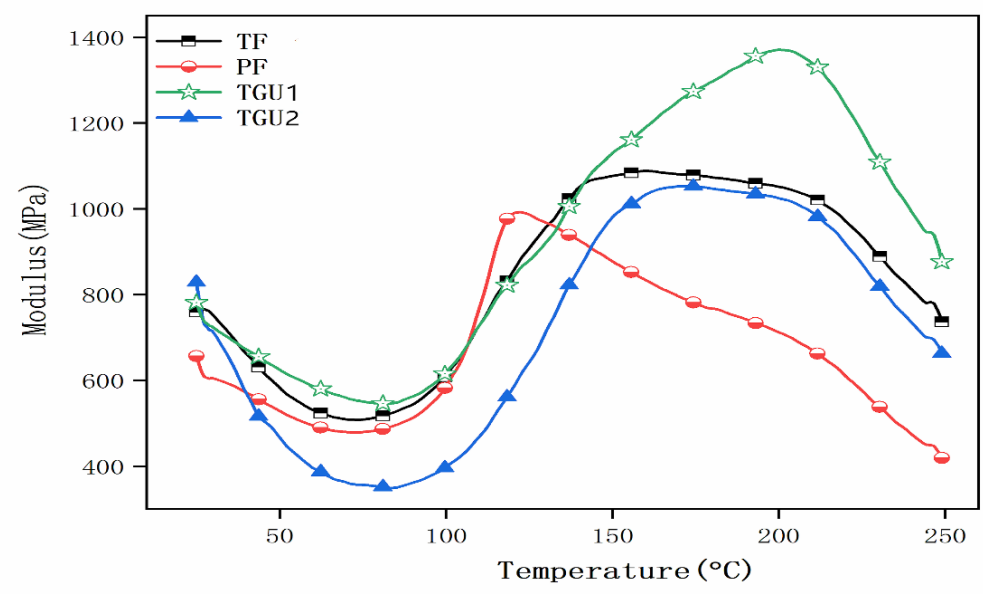

Figure 8: Thermomechanical (TMA) traces of the different resins.

The thermal degradation profiles of the resins along with MT are shown in Figure 9. The temperatures corresponding to mass losses of $5 \%, 15 \%, 30 \%$ and $50 \%$ are referred to as $T 5 \%, T 15 \%, T 30 \%$ and $T 50$ $\%$, respectively. The degradation behaviour was almost identical in all cases, and for better understanding, it can be divided into two portions: from r.t. to $200^{\circ} \mathrm{C}$ and from $200{ }^{\circ} \mathrm{C}$ to $800^{\circ} \mathrm{C}$. Thus, the degradation of cured TGU1 resin proceeded slowly till $200^{\circ} \mathrm{C}$ due to efficient curing and higher cross-linking density, especially when compared with TGU2, while the PF, TF and TGU2 resins proceeded faster in the same range. Beyond $200{ }^{\circ} \mathrm{C}$ and up to the end of the run at $800{ }^{\circ} \mathrm{C}$, the degradation phenomena of TGU1 and TGU2 was almost identical and showed less resistance to thermal degradation compared to TF and PF resins, inferring that the presence of urea as part of the structure is responsible for higher sensitivity to degradation under heating. The residual weights of the traces in each case indicate that TGU1 and TGU2 are the resins most sensitive to heat and loss of weight, especially at higher temperatures.

Nevertheless, considering the balanced properties of reasonable thermal resistance and developed mechanical strength observed from TMA and TGA results, it can be deduced that TGU1 resin is a good candidate for grinding wheel applications. 


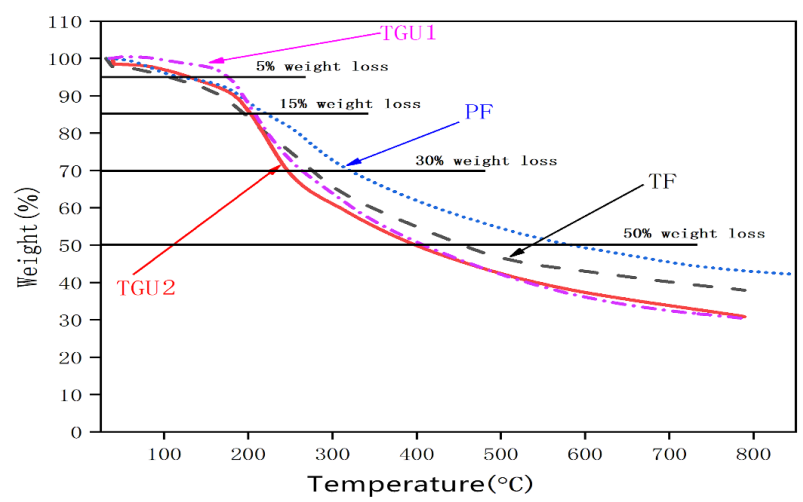

Figure 9: Thermogravimetric traces of cured TGU1, TGU2, TF and PF resins.

\section{Observations of grinding wheels}

TGU resin-based grinding wheels were prepared in the laboratory. Interestingly, most of them showed almost no cracks on the surface. TGU1 is shown as an example in Figure 10. Surface examination via scanning electron microscopy (SEM) is shown in Figure 11. The surface of the TGU2-G grinding wheel revealed obvious cracks in the matrix (Figure $11 \mathrm{~b}$, marked with red circles). In contrast, no cracks were found in TGU1-G, TF-G and PF-G (Figure 11a, Figure 11c, Figure 11d). As previously described, the gel time of TGU2 resin at $100^{\circ} \mathrm{C}$ was longer compared to that of the other resins, with two curing peaks observed in the curing scan, which indicates that the condensation reaction between urea, glyoxal and tannin under alkaline conditions was difficult to complete in a rotary evaporator at $60^{\circ} \mathrm{C}$. This reveals that more reaction steps have been established in the pressing machine at $150{ }^{\circ} \mathrm{C}$, and the liberated free water formed cracks and defects in the grinding wheel. Furthermore, numerous holes were found in TF-G and PF-G compared to TGU1-G. In the case of TF resin, the self-condensation of furfuryl alcohol predominated to such an extent that there was little or no co-reaction with tannin. This caused the TF-G resin mixture to entrap air; thus, during the curing process, numerous holes formed on the surface (Figure 11c, marked with arrow). Glyoxal and urea are known to be very reactive to tannin under acidic conditions. Thus, fewer holes were detected in TGU1-G. For PF-G, very few holes were found (Figure 11d, marked with arrow) because of its high viscosity (check the data in Figure 4). $\mathrm{SiO}_{2}$ particles could not be detected despite their high mass ratio with respect to the resin, indicating homogenous blending of the abrasive particles and most likely excessive surface reactions via their hydroxyl groups, leading to embedding within the resin.

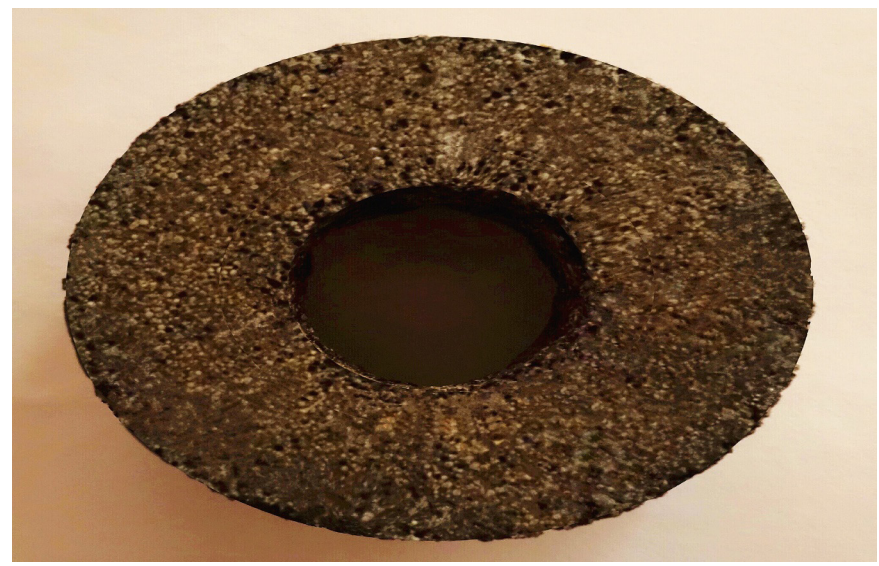

Figure 10: Physical appearance of a grinding wheel based on TGU1 resin matrix. 

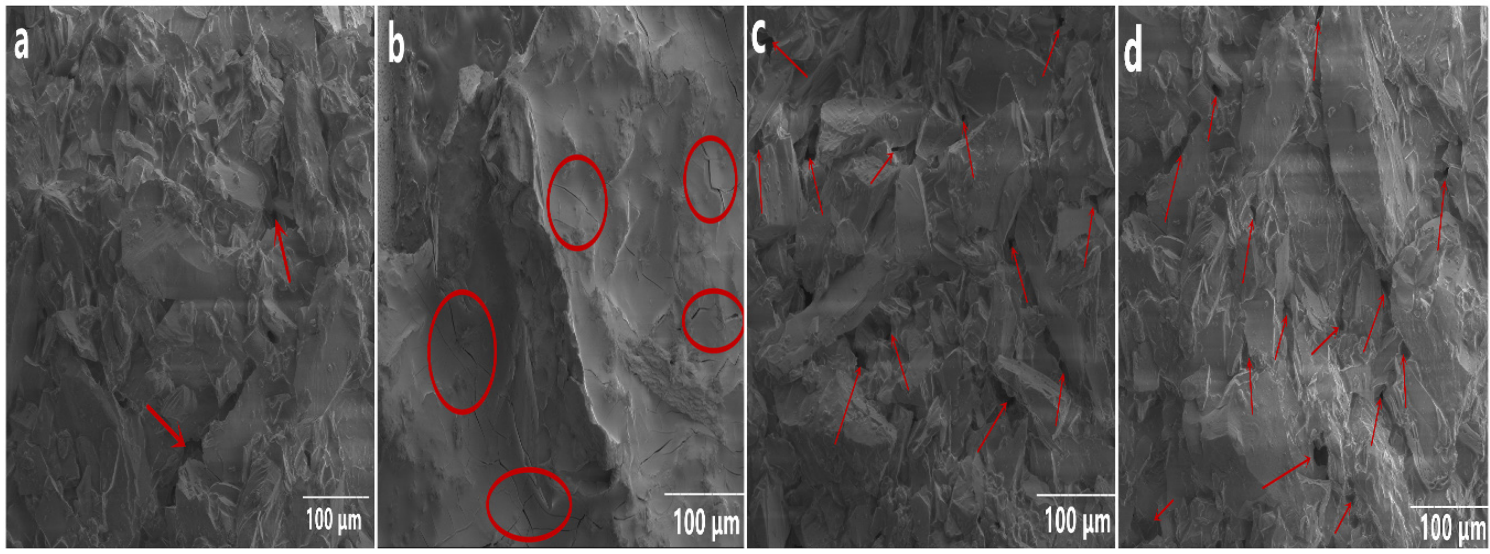

Figure 11: SEM micrographs of (a)TGU1-G, (b)TGU2-G, (c)TF-G and (d) PF-Ggel.

\section{Brinell hardness, compression and abrasion evaluation}

Figure 12 shows the Brinell hardness and compressive strength of the grinding wheels. Compared to TF-G prepared in the laboratory and the TF resin-based grinding wheel reported by Lagel et al. (2015a), substitution of furfuryl alcohol with urea and glyoxal in a tannin resin system for preparing TGU1-G can decrease the cost. Moreover, TGU1-G had a higher compressive strength (221,35 MPa) and comparable hardness (10,38 DaN/ $\mathrm{mm}^{2}$ ) compared to TF-G (212,37 MPa and 10,53 DaN/ $\mathrm{mm}^{2}$, respectively). More defects and holes developed on the TF-G surface compared withTGU1-G, definitely indicating lower compressive strength (Figure 11c). The compressive strength and $H_{\mathrm{B}}$ of TF-G were higher compared to those of TGU2-G, corroborating that glyoxal reacts inefficiently with urea and tannin to form a network structure with enough strength to reinforce the grinding wheel.

The low reactivity of tannin under alkaline conditions greatly hampered the reaction between tannin, glyoxal and urea; this can be deduced from the numerous cracks that appeared on the TGU2-G surface (Figure 11b). This explains the reason for the compressive strength of TGU2-G being lower compared to that of TGU1-G. Moreover, TGU1-G and TF-G showed excellent hardness and compressive strength compared to PF-G, indicating the highquality of the prepared grinding wheel.

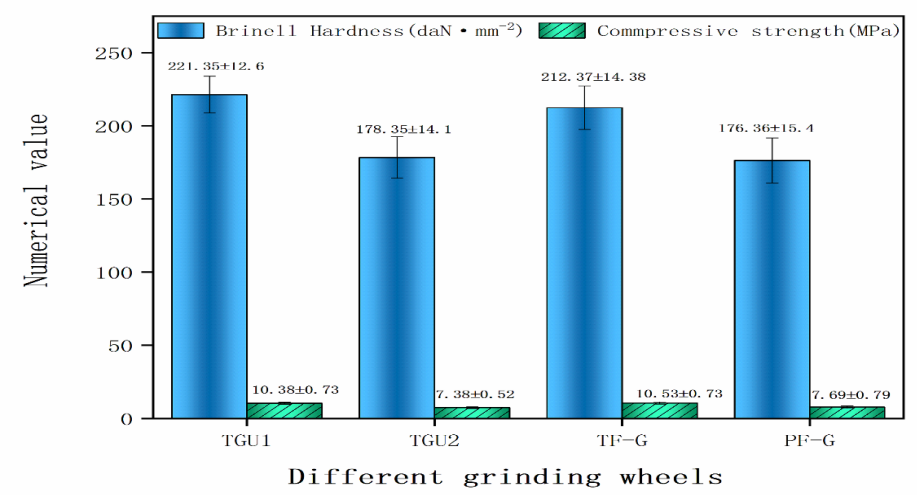

Figure 12: Brinell hardness $\left(H_{\mathrm{B}}\right)$ and compressive strength of the grinding wheels.

Table 3 presents the abrasion (both wet and dry) resistance of the grinding wheels. A commercial Taber Calibrade wheel (H-18) was also tested for comparison with our laboratory-made grinding wheels. In the dry state, TGU1-G with a mass loss of $0,208 \%$ exhibited better wear resistance compared to TF-G with a mass loss of $0,285 \%$ and TGU2-G with a mass loss of $0,585 \%$; this is due to homogenous blending and excellent bonding between the resin and $\mathrm{SiO}_{2}$ particles. A high $H_{\mathrm{B}}$ means better resistance to abrasion as can be proved by the lower mass loss of TGU1-G compared with that of TF-G at $200^{\circ} \mathrm{C}$; this is attributable to mass loss as a 
result of high temperature during rotation of the grinding wheel. We also compared TGU1-G with oil-derived resin-based abrasive materials such as PF-G. The corresponding wear index of TGU1-G $(11,87 \mathrm{E}-05)$ was close to that of PF-G $(11,36 \mathrm{E}-05)$, which showed a higher mass loss compared toTGU1-G. Therefore, TGU1-G is a promising abrasive material because of its high wear index, which can be up to three times that of the commercial Taber Calibrade wheel (H-18).

Table 3: Abrasion resistance of the grinding wheels.

\begin{tabular}{|c|c|c|c|c|c|}
\hline $\begin{array}{c}\text { Grinding Wheel } \\
\text { type }\end{array}$ & $\begin{array}{c}\text { Cycle } \\
(r)\end{array}$ & $\begin{array}{c}\text { Wear index } \\
\text { of grinding } \\
\text { wheels in dry } \\
\text { state }\end{array}$ & $\begin{array}{c}\text { Mass loss of } \\
\text { grinding } \\
\text { wheels in dry } \\
\text { state }(\%)\end{array}$ & $\begin{array}{c}\text { Wear index } \\
\text { of grinding } \\
\text { wheels in wet } \\
\text { state }\end{array}$ & $\begin{array}{c}\text { Mass loss of } \\
\text { grinding wheels in wet } \\
\text { state(\%) }\end{array}$ \\
\hline TGU1-G & 500 & $\begin{array}{c}11,87 \pm 0,26 \mathrm{E}- \\
05\end{array}$ & $0,208 \pm 0,009$ & $11,53 \pm 0,23 \mathrm{E}-05$ & $0,213 \pm 0,011$ \\
\hline TGU2-G & 500 & $\begin{array}{c}9,36 \pm 0, \\
13 \mathrm{E}-05\end{array}$ & $0,585 \pm 0,021$ & $8,21 \pm 0,13 \mathrm{E}-05$ & $0,737 \pm 0,023$ \\
\hline TF-G & 500 & $\begin{array}{c}11,59 \pm 0,21 \\
\mathrm{E}-05\end{array}$ & $0,285 \pm 0,014$ & $11,63 \pm 0,20 \mathrm{E}-05$ & $0,286 \pm 0,012$ \\
\hline PF-G & 500 & $\begin{array}{c}11,36 \\
\pm 0,19 \mathrm{E}-05\end{array}$ & $0,253 \pm 0,008$ & $9,78 \pm 0,21 \mathrm{E}-05$ & $0,437 \pm 0,012$ \\
\hline $\begin{array}{c}\text { Reference: Wheel } \\
\text { H-18 }\end{array}$ & 500 & $\begin{array}{c}3,92 \pm 0,21 \mathrm{E}- \\
05\end{array}$ & $0,107 \pm 0,005$ & $/$ & $/$ \\
\hline
\end{tabular}

Under wet conditions after immersion in water, the mass loss $(0,213 \%)$ and wear index $(11,53 \mathrm{E}-05)$ of TGU1-G were close to the mass loss $(0,208 \%)$ and wear index $(11,87 \mathrm{E}-05)$ of TGU1-G before immersion in water, indicating that the grinding wheel prepared from theTGU1 resin matrix exhibits good water resistance. Moreover, the mass loss of TFU1-G after immersion in water was lower than that of TF-G in dry state or after immersion in water. In contrast, TGU2-G exhibited weak water resistance, indicated by its higher mass loss and lower wear index after immersion in water compared to those in the dry state.

Compared to the previously reported grinding wheel (which was formulated using TF resin) with a wear index of 9,79E-05 (Lagel et al. 2015b), the wear resistance of the more cost-effective TGU1-G prepared in this study was higher considering the high viability of its formulation for industrial production.

\section{CONCLUSIONS}

In this study, a resin mixture comprising urea, glyoxal and tannin (MT) with reasonable viscosity at low curing temperature was prepared by incorporating $\mathrm{SiO}_{2}$ particles. This new route simplifies the fabrication of an environmentally friendly, bio-based grinding wheel in terms of processing time and cost, considering that tannin is a renewable forest product. The MT-based grinding wheels showed good appearance with no visual cracks and few holes. Useful features such as high hardness, strong resistance to compression and better abrasion resistance compared to PF-based grinding wheel and commercial Taber Calibrade wheel (H-18) make the introduced procedure more viable. The excellent thermal resistance of the grinding wheel, with $\sim 2 \%$ mass loss at $200^{\circ} \mathrm{C}$, is an indicator of distinct homogeneous cross-linking of the network structure and further reinforcing provided by the abrasive $\mathrm{SiO}_{2}$ particles. The low cost and environmentally friendly fabrication of the MT-based grinding wheel renders it a very promising bio-based abrasive product to replace industrially applicable PFbased grinding wheels.

\section{ACKNOWLEDGMENTS}

This study was supported by the Youth Fund of the Natural Science Foundation of China (Grant No. 31800482), Yunnan Provincial Natural Science Foundation (Grant No. 202001AT070095, 2018FG001-095), Yunnan Provincial Youth Talent Promotion Project and the Yunnan Provincial Youth and Middle-age Reserve Talents of Academic and Technical Leaders (2019HB026).

\section{REFERENCES}

Abdullah, U.H.B.; Pizzi, A. 2013. Tannin-furfuryl alcohol wood panel adhesives without formaldehyde. European Journal of Wood and Wood Products 71(1): 131-132. https://link.springer.com/article/10.1007/ s00107-012-0629-4 
Beckert, M.; Menzel, M.; Töll, F.J.; Bruchmann, B.; Mülhaupt, R. 2015. Nitrogenated graphene and carbon nanomaterials by carbonization of polyfurfuryl alcohol in the presence of urea and dicyandiamide. Green Chemistry 17: 1032-1037. http://dx.doi.org/10.1039/c4gc01676a

Celzard, A.; Zhao, W.; Pizzi, A.; Fierro, V. 2010. Mechanical properties of tannin-based rigid foams undergoing compression. Materials Science and Engineering: A 527(16): 4438-4446. http://dx.doi.org/10.1016/j. msea.2010.03.091

Deng, S.D.; Pizzi, A.; Du, G.B.; Zhang, J.Z.; Zhang, J. 2014a. Synthesis, Structure, and Characterization of Glyoxal-Urea-Formaldehyde Cocondensed Resins. J Applied Polymer Science: 131(21): 41009-41016. http://dx.doi.org/10.1002/app.41009

Deng, S.D.; Du, G.B.; Li, X.H.; Pizzi, A. 2014b. Performance and reaction mechanism of zero formaldehyde-emission urea-glyoxal (UG) resin. Journal of the Taiwan Institute of Chemical Engineers 45(4): 20292038. http://dx.doi.org/10.1016/j.jtice.2014.02.007

Hussein, A.S.; Ibrahim, K.I.; Abdulla, K.M. 2011. Tannin-Phenol Formaldehyde Resins as Binders for Cellulosic Fibers: Mechanical Properties. Nat Resource 2(2): 98-101. http://dx.doi.org/10.4236/nr.2011.22013

Klocke, F.; Soo, S.L.; Karpuschewski, B.; Webster, J.A.; Novovic, D.; Elfizy, A.; Axinte, D.A.; Tönissen, S. 2015. Abrasive machining of advanced aerospace alloys and composites. CIRP Annals 64(2): 581-604. http://dx.doi.org/10.1016/j.cirp.2015.05.004

Lacoste, C.; Basso, M.C.; Pizzi, A.; Laborie, M.P.; Garcia, D.; Celzard, A. 2013. Bioresourced pinetannin/furanic foams with glyoxal and glutaraldehyde. Industrial Crops and Products 45: 401-405. http://dx.doi.org/10.1016/j.indcrop.2012.12.032

Lacoste, C.; Pizzi, A.; Laborie, M.P.; Celzard, A. 2014. Pinus pinaster tannin/furanic foams: Part II Physical properties. Industrial Crops and Products 61: 531-536. http://dx.doi.org/10.1016/j.indcrop.2014.04.034

Lagel, M.C.; Pizzi, A.; Basso, M.C.; Abdalla, S. 2015a. Development and characterization of abrasive grinding wheels with a tannin-furanic resins matrix. Ind Crop Prod 65: 343-348. http://dx.doi.org/10.1016/j. indcrop.2014.11.020

Lagel, M.C.; Zhang, J.; Pizzi, A. 2015b. Cutting and grinding wheels for angle grinders with a bioresin matrix. Industrial Crops and Products 67: 264-269. http://dx.doi.org/10.1016/j.indcrop.2015.01.046

Li, C.; Zhang, J.; Yi, Z.; Yang, H.; Zhao, B.; Zhang, W.; Li, J. 2015. Preparation and characterization of a novel environmentally friendly phenol-formaldehyde adhesive modified with tannin and urea. International Journal of Adhesion and Adhesives 66: 26-32. http://dx.doi.org/10.1016/j.ijadhadh.2015.12.004

Li, M.C.; Zhang, F.L.; Zhou, Y.M.; Li, W.X.; Wu, S.X.; Wu, S.H. 2020. Preparation and performance of resin-bonded grinding wheel with braze-coated diamond grits. Diamond and Related Materials 101: 107619. https://doi.org/10.1016/j.diamond.2019.107619

Li, W.; Lee, L.J. 2000. Low temperature cure of unsaturated polyester resins with thermoplastic additives: I. Dilatometry and morphology study. Polymer 41(2): 685-696. http://dx.doi.org/10.1016/s00323861(99)00177-9

Li, X.; Nicollin, A.; Pizzi, A.; Zhou, X. J.; Sauget, A.; Delmotte, L. 2013. Natural tannin-furanic thermosetting moulding plastics. RSC Advances 3(39): 17732-17740. http://dx.doi.org/10.1039/c3ra43095b

Luo, M.; Li, Y.W.; Sang, S.B.; Zhao, L.; Jin, S.L.; Li, Y.B. 2012.In situ formation of carbon nanotubes and ceramic whiskers in Al2O3-C refractories with addition of Ni-catalyzed phenolic resin. Materials Science and Engineering: A 558: 533-542. https://doi.org/10.1016/j.msea.2012.08.044

Manoharan, S.; Ramadoss, G.; Suresha, B.; Vijay, R. 2015. Influence of fiber reinforcement and abrasive particle size on three-body abrasive wear of hybrid friction composites. Applied Mechanics and Materials 766-767: 156-161. http://dx.doi.org/10.4028/www.scientific.net/AMM.766-767.156 
Moubarik, A.; Pizzi, A.; Allal, A.; Charrier, B. 2009. Corn starch and tannin in phenol-formaldehyde resins for plywood production. Industrial Crops and Products 30(2): 188-193. http://dx.doi.org/10.1016/j. indcrop.2009.03.005

Pasch, H.; Pizzi, A.; Rode, K. 2001. MALDI-TOF mass spectrometry of polyflavonoid tannins. Polymer 42(18): 7531-7539. http://dx.doi.org/10.1016/s0032-3861(01)00216-6

Pizzi, A. 1994. Advanced Wood Adhesives Technology. Advanced wood adhesives technology. M. Dekker. http://dx.doi.org/10.1016/0143-7496(95)90002-0

Pizzi, A.; Tondi, G.; Pasch, H. 2008. MALDI-TOF structure determination of complex thermoset networks-polyflavonoid tannin-furanic rigid foams. J Appl Polym Sci 110(3): 1451-1456. http://dx.doi.org/10.1002/app.28545

Robie, N.P. 1957. Referencing styles for journals-abrasive bodies. U. S. Patent, 2806772. U.S. Patent, 3925034A.

Rowse, R.A.; Stinchfield, C.P. 1959. Referencing styles for journals-phenolic resin boned grinding wheels. U.S. Patent, 3041156.

Sauget, A.; Zhou, X.; Pizzi, A. 2014.Tannin-resorcinol-formaldehyde resin and flax fiber biocomposites. J Renew Mater 2(3): 173-181. http://dx.doi.org/10.7569/JRM.2013.634128

Tondi, G. 2017. Tannin-based copolymer resins: synthesis and characterization by solid state 13C -NMR and FT-IR Spectroscopy. Polymer 9(6): 223-239. http://dx.doi.org/10.3390/polym9060223

Tondi, G.; Pizzi, A.; Masson, E.; Celzard, A. 2008a. Analysis of gases emitted during carbonization degradation of polyflavonoid tannin/furanic rigid foams. Polym Degrad Stabil 93(8): 1539-1543. http://dx.doi.org/10.1016/j.polymdegradstab.2008.05.016

Tondi, G.; Pizzi, A.; Olives, R. 2008b. Natural tannin-based rigid foams as insulation for doors and wall panels. Maderas-Cienc Tecnol 10(3): 219-227. http://dx.doi.org/10.4067/s0718-221x2008000300005

Tondi, G.; Pizzi, A.; Pasch, H.; Celzard, A. 2008c. Structure degradation, conservation and rearrangement in the carbonisation of polyflavonoid tannin/furanic rigid foams-A MALDI-TOF investigation. Polym Degrad Stabil 93(5): 968-975. http://dx.doi.org/10.1016/j.polymdegradstab.2008.01.024

Wang, H.Y.; Lu, R.G.; Huang, T.; Ma, Y.N.; Cong, P.H.; Li, V. 2011. Effect of grafted polytetrafluoroethylene Nanoparticles on the mechanical and tribological performances of phenol resin. Mat Sci Eng A 528(22): 6878-6886. http://dx.doi.org/10.1016/j.msea.2011.05.049

Wu, Z.G.; Lei, H.; Cao, M.; Xi, X.D.; Liang, J.K.; Du, G.B. 2016. Soy-based adhesive cross-linked by melamine-glyoxal and epoxy resin. J Adhesion Sci Technol 19(30): 2120-2129. http://dx.doi.org/10.1080/016 94243.2016.1175247

Zhang, J.; Luo, H.; Pizzi, A.; Du, G.B.; Deng, S.D. 2015. Preparation and Characterization of Grinding Wheels Based on a Bioresin Matrix and Glass Sand Abrasives. Bioresources 10(3): 5369-5380. http://dx.doi.org/10.15376/biores.10.3.5369-5380

Zhang, J.; Xi, X.D.; Liang, J.K.; Pizzi, A.; Du, G.B.; Deng, S.D. 2019. Tannin-based adhesive crosslinked by furfuryl alcohol-glyoxal and epoxy resins. Int J Adhes Adhes 94: 47-52. http://dx.doi.org/10.1016/j. ijadhadh.2019.04.012

Zhou, X.J.; Li, B.; Xu, Y.; Essawy, H.; Wu, Z.G.; Du, G.B. 2019. Tannin-furanic resin foam reinforced with cellulose nanofibers (CNF). Industrial Crops and Products 134: 107-112. http://dx.doi.org/10.1016/j. indcrop.2019.03.052

Zuo, Y.F.; Liu, W.J.; Xiao, J.H.; Li, X.J.; Zhao, X.; Wu, Y.Q. 2019.NaOH and $\mathrm{Ba}(\mathrm{OH})_{2}$ Compound Catalyzed PhenolResorcinol-Formaldehyde Copolycondensation Resin Adhesive for Recombined Bamboo. Journal of Wuhan University of Technology-Mater. Sci Educ-Netherlands 34(2): 459-464. http://dx.doi. org/10.1007/s11595-019-2074-2 